\title{
Giant Ovarian Tumor Presenting as a Huge Abdomino-Pelvic Mass in a Teenage Girl: A Case Report
}

\author{
M JAMALUDDIN ${ }^{\mathrm{a}}$, HH AHMED
}

\begin{abstract}
:
Ovarian cysts are common causes of lower abdominal pain and abdominal distention in females. While most of them are benign and rarely grow immensely to achieve a huge size, they may be neoplastic in origin, reaching enormous dimensions with minimum or without raising any symptoms.Here, we present an interesting case of a 19-year-old female,who presented with huge
\end{abstract}

\section{Introduction:}

Giant or huge ovarian cyst are benign tumors of ovaries which are more than 10 to $15 \mathrm{~cm}$ in diameter and are very rare in younger age. ${ }^{1,2}$ They are also very rare, about less than $1 \%$ in pregnant woman. ${ }^{3}$ Due to advance investigation techniques, now a days, they are usually diagnosed early and treated early. ${ }^{2}$ Very rarely they attain huge size causing abdominal symptoms and signs. ${ }^{4}$ These patients usually present with abdominal pain, discomfort, distention and pressure symptoms. ${ }^{5,} 6$ Sometimes, they are misdiagnosed as other cysts, like pancreatic cyst $^{7}$,hydatid cyst or mesenteric cyst. Most of the huge ovarian cysts are benign but few are malignant and some of them are intermediate type as well. They are diagnosed very easily by ultrasonography but some time they need more advance imaging like computed tomography (CT)scan or magnetic resonance imaging (MRI) for their diagnosis. ${ }^{8}$ Serology including Echinococcus titer, CA-125, CA-19-9 or other tumor markers may need for further confirmation. Huge ovarian tumors are

a. Prof. Dr. Muhammad Jamaluddin, Professor of Surgery, HOD Surgical Unit-II \& Urology, KMDC \& Abbasi Shaheed Hospital

b. Dr. Hajrah Hilal Ahmed, Post Graduate Trainee (FCPS-II Surgery), Abbasi Shakeed Hospital

Address of Correspondence: Prof. Dr. Muhammad Jamaluddin, Professor of Surgery, HOD Surgical Unit-II \& Urology, KMDC \& Abbasi Shaheed Hospital, Cell: +92300-2167612, E-mail: drmjdin@hotmail.com

Received: 23 June, 2020

Accepted: 11 March, 202 abdominal swelling and pain in whole abdomen from whom a $9.1 \mathrm{~kg}$ borderline mucinous ovarian cyst, occupying the whole abdominal cavity was removed.

Key words: Huge ovarian cyst, abdominal pain, abdominal distention, ovarian tumor, neoplastic.

(J Bangladesh Coll Phys Surg 2021; 39: 137-141)

DOI: https://doi.org/10.3329/jbcps.v39i2.52394

conventionally treated by elective laparotomies but now a days laparoscopic treatment are becoming gold standard for them. ${ }^{9-11}$

\section{Case Report:}

A 19-year-old unmarried female was referred to our Surgical Outpatient Department from the Gynecology and Obstetrics Outpatient Department for opinion.She had a history of gradually increasing abdominal swelling since 6 months. As the size of the swelling increased, the patient developed vague abdominal pain of dull aching character, more so in the left lower abdomen. There was neither a history of contact with sheep or dogs nor was there a family history of similar complaints or living in the rural area.She attained menarche at twelve years of age with a regular 5/28-day menstrual cycle associated with dysmenorrhea during bleeding. The review of systems was unremarkable especially for such symptoms as weight loss, vaginal discharge, urinary symptoms, bowel symptoms or dyspnea etc.

On general physical examination, she was healthy and vitally stable with no acute distress with a body weight of $45 \mathrm{Kg}$. She was mildly anemic with no other positive findings. On examination of the abdomen, she had a markedly distended abdomen revealing a huge spherical mass arising from the pelvis up to the epigastrium. This was a non-tender, cystic mass having smooth surface with slight mobility in the transverse direction. 
Baseline investigations were unremarkable except a hemoglobin of $10.8 \mathrm{gm} / \mathrm{dl}$. Markers for ovarian tumors were done;CA-125, CEA, CA-19-9:all were within normal range. Ultrasoundwas suggestive of a huge anechoic mass covering the whole abdomen with internal echoes, septations and multiple daughter cysts. Uterus was normal in size measuring $7.8 \mathrm{~cm} \times 2.7 \mathrm{~cm} \times 3.0 \mathrm{~cm}$ and seen separate from the mass. The ovaries were not visualized. Minimal amount of free fluid in the pelvis was seen. Abdominal organs were compressed by the mass with a moderate right-sided hydronephrosis. Differential diagnoses suggested by the ultrasound included hydatid cyst and ovarian cystadenoma/cystadenocarcinoma.CT scan of the abdomen and pelvis showed a large well defined cystic lesion in the abdomen extending well into the pelvis and up into the epigastrium having internal well-defined cystic areas of varying attenuation predominantly along its left lateral margin (Figures $1,2 \& 3)$. The mass was reported to be compressing the aorta at its bifurcation and the right ureter causing moderate hydronephroureter. The left ovary was not separately delineated from the mass. Minimal amount of free fluid was present in the pelvis. Findings could be suggestive of complex ovarian cyst however the differential diagnosis includedhydatid cyst.The patient tolerated the procedure well and had an uneventful postoperative period, being discharged on the $5^{\text {th }}$ postoperative day.

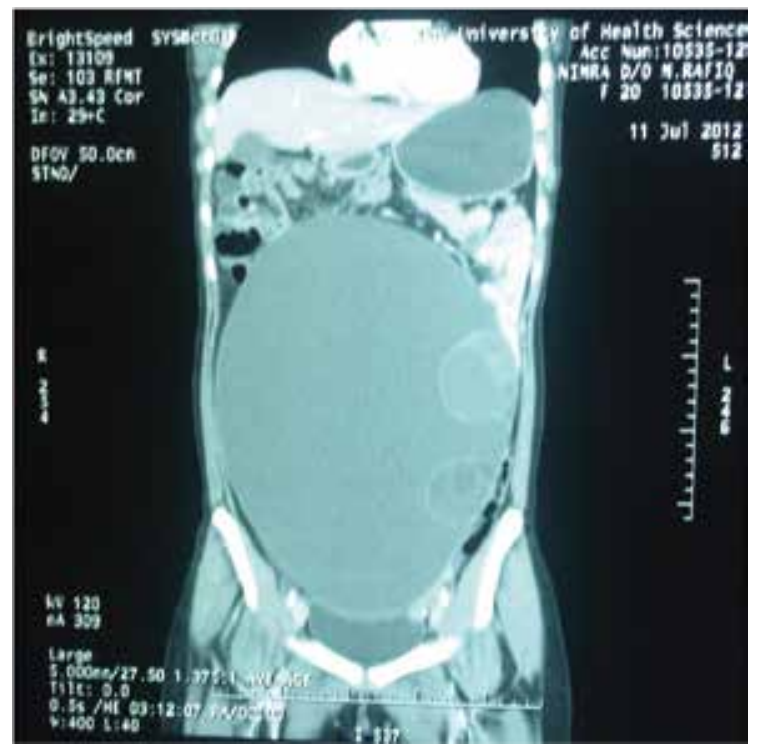

Figure 1.CT scan abdomen showing huge cyst

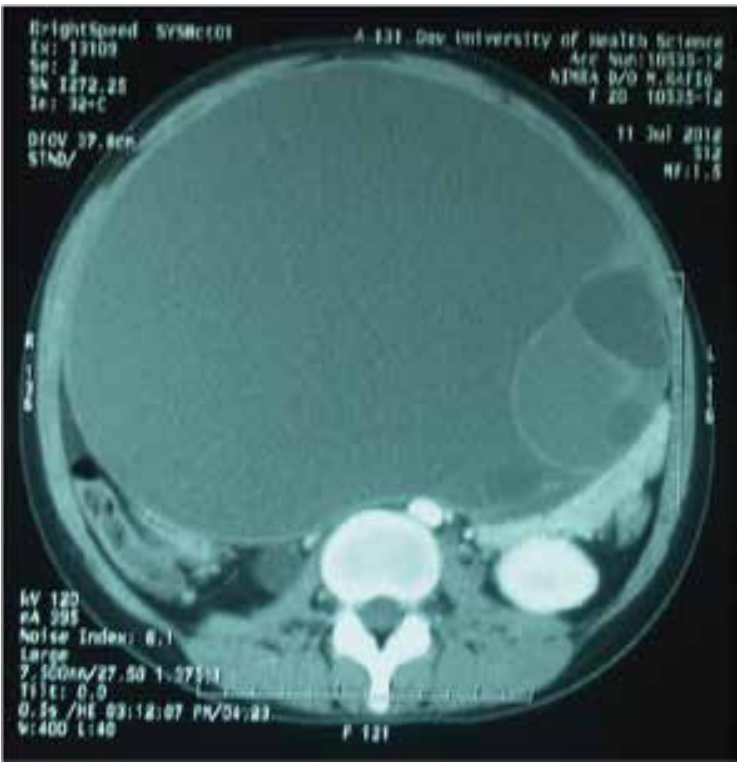

Figure 2. CT scan abdomen showing cyst

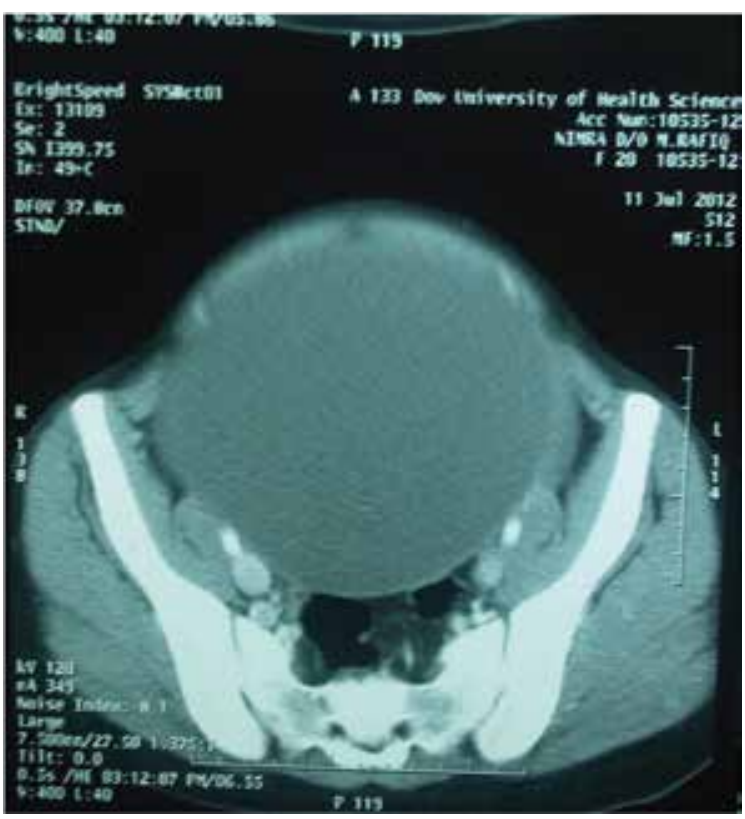

Figure 3. CT scan showing abdomino-pelvisc cyst

Echinococcusserology was advised which came back negative.Due to suspicion of a possibility of hydatidcyst and relationship of the mass with the aortic bifurcation, the patient was admitted under care of Surgical Department and elective surgery was planned.

The patient underwent elective exploratory laparotomy where a large tense, smooth surfaced, shiny ovarian cystic mass was found(Figure 4) 
arising from the left ovarian pedicle and extending up to the undersurface of the diaphragm, having flimsy adhesions to surrounding structures. The mass was delivered from the abdominal cavity and after ligation of the left ovarian pedicle, a left salpingo-oophorectomy was performed(Figure 5).The right ovary, fallopian tube and uterus were found to be normal but small number of tiny cysts were present over the surface of right ovary which were left as it is. The rest of the peritoneal cavity was unremarkable.The abdomen was closed without drainage.

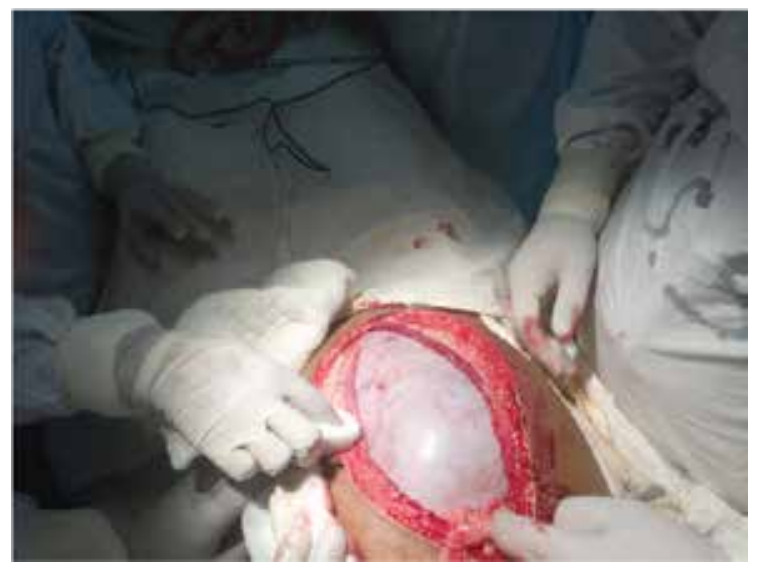

Figure 4. Per-operative image just after incision

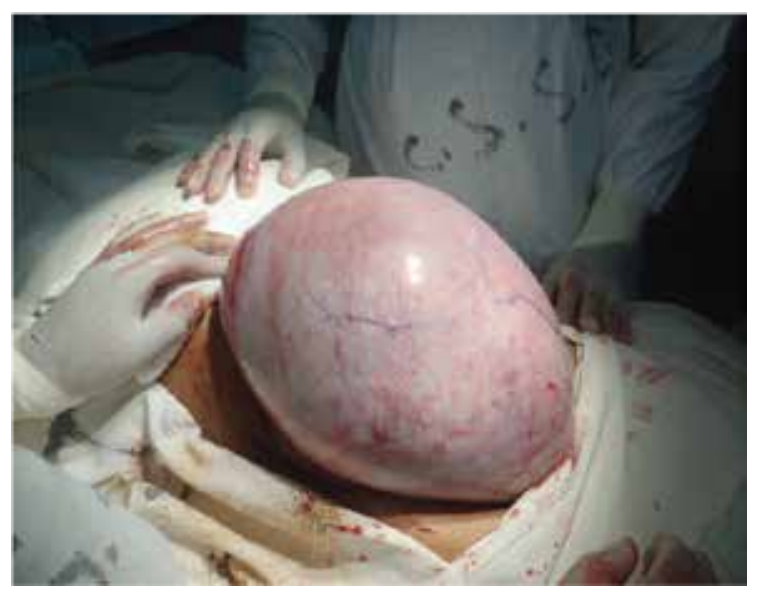

Figure 5. Per-operative image showing huge left ovarian mass

The mass weighted $9.1 \mathrm{~kg}$ ovarian cyst of $25 \mathrm{~cm} \times 15$ $\mathrm{cm} \times 13 \mathrm{~cm}$ dimensions showing borderline mucinous neoplasm on histopathology. The ovarian capsule was intact without surface epithelial proliferation. The patient was referred to
Gynae-Oncology for further management and expert opinion, where she was kept under strict follow up.

\section{Discussion}

Within the diverse group of ovarian neoplastic lesions, $15-20 \%$ of the ovarian epithelial variety is comprised of the borderline subset, having a reported incidence of $1.5-2.5$ per 100,000 people per year. ${ }^{12}$ Within this subset of borderline tumors, the mucinous variety represents about $32 \%$ of all cases ${ }^{12}$ making it a relatively uncommon tumor.

The mean age of presentation of the mucinous variety of borderline tumors is 45 years with nulliparity a risk factor at this age. There is alsoan association with KRAS gene mutation in up to $60 \%$ cases $^{12}$.

Being amongst the most difficult of ovarian tumors for the surgical pathologist to interpret ${ }^{13}$, the borderline variety, although said to have uncertain malignant potential ${ }^{14}$, generally have excellent prognosis. ${ }^{13}$ These neoplasms may uncommonly be the cause of a large abdominal cystic mass and may occasionally be referred to the General Surgeon for an opinion. The standard work-up in such cases should include imaging with ultrasound/CT scanning.

Because ovarian tumors and hydatidcyst disease have many radiological features similar to each other ${ }^{15}$, further investigations of Echinococcus serology for hydatidosis and tumor markers for ovarian neoplasms are warranted.

The final diagnosis may, nevertheless, be compounded by the fact that Echinococcusserology is false-negative in up to $25 \%$ cases of hydatidosis ${ }^{16}$ and tumor markers may not be elevated in borderline ovarian tumors ${ }^{17}$ as happened in this case.

However in addition to CA-125, CA 19-9 and CEA levels are also the part of the work up as CA-125 levels have be found to correlate more with advanced stage of borderline tumors and CA 19-9 and CEA levels are more frequently elevated in early stage disease. ${ }^{17}$ Germ cell tumor markers like B-HCG and AFP should also have been part of workup as these tumors are more common in adolescents. 
Therefore, these cases may be found under care of the General Surgeon as an abdominal mass due to suspicion of alternate diagnosis of hydatid, age of presentation not correlating with ovarian neoplasms, inconclusive imaging findings, and negative tumor markers.

The relationship of the mass with surrounding structures may also require involvement of the General Surgeon and therefore the General Surgeon should have a thorough knowledge of operative management of these neoplasms. Per-operatively, an important point is to thoroughly examine the appendix, the large bowel and peritoneal cavity in general to search for implants indicating advanced disease and to rule out the possibility of secondary borderline mucinous ovarian neoplasm, which may arise from the large bowel or appendix.

Initially laparotomy was the gold standard treatment for the huge ovarian tumors but now with the advancement of minimally invasive technique, laparoscopic treatment has become the gold standard method either single port or multi-port technique. ${ }^{11}$ But due to limited resource and in under developed countries laparotomy is still used as gold standard treatment method and histopathology is gold standard mode of diagnosis in all cases. ${ }^{9,18}$

\section{Conclusion}

Huge ovarian cysts are very rare in teen age girls and early advance modalities should be used to diagnose it early and early treatment should be given to avoid major intervention. Whatever the clinical or image findings are, the standard for treatment and confirmatory diagnosis is exploratory laparotomy followed by histopathology.

\section{References}

1. Uyanikoglu H, Dusak A. A Huge Ovarian Dermoid Cyst: Successful Laparoscopic Total Excision. J ClinDiagn Res. 2017;11(8):QD03-QD05. doi:10.7860/ JCDR/2017/29262.10436. https://doi.org/10.7860/JCDR/ 2017/29262.10436, PMid:28969215 PMCid:PMC5620856

2. Yeika EV, Efie DT, Tolefac PN, Fomengia JN. Giant ovarian cyst masquerading as a massive ascites: a case report. BMC Res Notes. 2017;10(1):749. Published 2017 Dec 19. doi:10.1186/s13104-017-3093-8. https://doi.org/10.1186/s13104-017-3093-8 PMid:29258579 PMCid:PMC5735515

3. Mishra S, Yadav M, Walawakar SJ. Giant Ovarian Mucinous Cystadenoma Complicating Term Pregnancy. JNMA J Nepal Med Assoc. 2018;56(210):629-632. https://doi.org/10.31729/jnma.3163 PMid:30376010

4. Buluş H, Akkoca M, Coskun A, Koçak E, Köklü S. Benign ovarian cyst presenting as a huge intraabdominal mass in an elderly postmenopausal woman. J Am Geriatr Soc. 2012;60(6):1170-1172. doi:10.1111/j.1532-5415.2012.03972.x. https://doi.org/ 10.1111/j.1532-5415.2012.03972.x, PMid:22690987

5. Mehboob M, Naz S, Zubair M, Kasi MA. Giant ovarian cyst--an unusual finding. J Ayub Med Coll Abbottabad. 2014;26(2):244-245.

6. Akhras LN, Akhras LN, Faroog S, AlSebay L. A 27-kg Giant Ovarian Mucinous Cystadenoma in a 72-Year-Old Postmenopausal Patient: A Case Report. Am J Case Rep. 2019;20:1601-1606. Published 2019 Nov 1. doi:10.12659/AJCR.917490. https://doi.org/ 10.12659/AJCR.917490,PMid:31672957 PMCid:PMC6849502

7. Tsai EM, Hsu SC, Chen HS, Wang JY, Lee JN. A huge pancreatic cystic adenoma misdiagnosed as an ovarian cyst. Kaohsiung J Med Sci. 1999;15(1):52-55.

8. Gwanzura C, Muyotcha AF, Magwali T, Chirenje ZM, Madziyire MG. Giant mucinous cystadenoma: a case report. J Med Case Rep. 2019;13(1):181. Published 2019 Jun 14. doi:10.1186/s13256-019-2102-z. https://doi.org/10.1186/s13256-019-2102-z PMid:31196215 PMCid:PMC6567598

9. Kim JS, Lee IO, Eoh KJ. Surgical technique for single-port laparoscopy in huge ovarian tumors: SW Kim's technique and comparison to laparotomy. ObstetGynecol Sci. 2017; 60(2):178-186. doi:10.5468/ogs.2017.60.2.178. https://doi.org/10.5468/ ogs . 2017.60 .2 .178$, P M id:28344959 PMCid:PMC5364100

10. Alobaid A, Memon A, Alobaid S, Aldakhil L. Laparoscopic management of huge ovarian cysts. ObstetGynecol Int. 2013;2013:380854. doi:10.1155/ 2013/380854. https://doi.org/10.1155/2013/380854 PMid:23766763 PMCid:PMC3665257

11. Yi SW. Minimally invasive management of huge ovarian cysts by laparoscopic extracorporeal approach. Minim Invasive Ther Allied Technol. 2012;21(6):429-434. doi:10.3109/13645706.2011. 
644855. https://doi.org/10.3109/13645706.2011.644855 PMid:22211916

12. Lalwani N, Shanbhogue AK, Vikram R, Nagar A, Jagirdar J, Prasad SR. Current Update on Borderline Ovarian Neoplasms. AJR Am J Roentgenol. 2010; 194: 330-6. https://doi.org/10.2214/AJR.09.3936 PMid:20093592

13. Hart WR. Mucinous Tumors of the ovary: a review. Int J GynecolPathol. 2005; 24: 4-25.

14. Moslemia MK, Yazdanib Z. A Huge Ovarian Cyst in a Middle-Aged Iranian Female. Case Rep Oncol. 2010; 3: 165-170. https://doi.org/10.1159/000314525 PMid:20740191 PMCid:PMC2919994

15. Sing P, Mushtaq D, Verma N, Mahajan NC. Pelvic Hydatidosis Mimicking a Malignant Multicystic Ovarian Tumor. Korean J Parasitol. 2010; 48: 263-265. https://doi.org/10.3347/kjp.2010.48.3.263 PMid:20877508 PMCid:PMC2945804
16. Siracusano A, Teggi A, Ortona E. Human cystic echinococcosis: old problems and new perspectives. InterdiscipPerspect Infect Dis. 2009;2009:474368. https://doi.org/10.1155/2009/474368 PMid:19888428 PMCid:PMC2771156

17. Nomelini RS, da Silva TM, Tavares Murta BM, Murta EF. Parameters of blood count and tumor markers in patients with borderline ovarian tumors: a retrospective analysis and relation to staging. ISRN Oncol. 2012;2012:947831. https://doi.org/10.5402/ 2012/947831, PMid:22577583 PMCid:PMC3345227

18. Mulisya O, Sikakulya FK, Mastaki M, Gertrude T, Jeff M. The Challenges of Managing Ovarian Cancer in the Developing World. Case Rep Oncol Med. 2020;2020:8379628. Published 2020 Mar 11. doi:10.1155/2020/8379628, https://doi.org/10.1155/ 2020/8379628, PMid:32231827 PMCid:PMC7086431 